\title{
Laboreal
}

Volume $9 \mathrm{~N}^{\circ} 1$ | 2013

Varia

\section{Modalidades de gestão do meio temporal em uma condução de processos múltiplos em situação dinâmica : uma pesquisa em empresas de horticultura}

Modalidades de gestión de la esfera temporal en la conducción de procesos múltiples en situación dinámica : una investigación en empresas hortícolas Modalités de gestion du milieu temporel dans une conduite de processus multiples en situation dynamique : une recherche dans des entreprises horticoles Management modalities of the temporal dimension in conducting multiple processes in a dynamic situation: a research at horticultural enterprises

\section{Valérie Zara-Meylan}

Tradutor: Adelaide Nascimento

\section{(2) OpenEdition}

\section{Journals}

Edição electrónica

URL: http://journals.openedition.org/laboreal/6188

DOI: 10.4000/laboreal.6188

ISSN: 1646-5237

Editora

Universidade do Porto

Refêrencia eletrónica

Valérie Zara-Meylan, « Modalidades de gestão do meio temporal em uma condução de processos múltiplos em situação dinâmica : uma pesquisa em empresas de horticultura », Laboreal [Online], Volume $9 \mathrm{~N}^{0} 1$ | 2013, posto online no dia 01 julho 2013, consultado o 24 setembro 2020. URL : http:// journals.openedition.org/laboreal/6188; DOI : https://doi.org/10.4000/laboreal.6188

Este documento foi criado de forma automática no dia 24 setembro 2020.

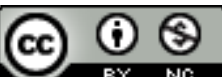

Laboreal está licenciado com uma Licença Creative Commons - Atribuição-NãoComercial 4.0 Internacional. 


\section{Modalidades de gestão do meio temporal em uma condução de processos múltiplos em situação dinâmica : uma pesquisa em empresas de horticultura}

Modalidades de gestión de la esfera temporal en la conducción de procesos múltiples en situación dinámica : una investigación en empresas hortícolas Modalités de gestion du milieu temporel dans une conduite de processus multiples en situation dynamique : une recherche dans des entreprises horticoles Management modalities of the temporal dimension in conducting multiple processes in a dynamic situation: a research at horticultural enterprises

\section{Valérie Zara-Meylan}

Tradução : Adelaide Nascimento

\section{REFERÊNCIA}

Zara-Meylan, V. (2012). Modalités de gestion du milieu temporel dans une conduite de processus multiples en situation dynamique : une recherche dans des entreprises horticoles. Thèse de doctorat en Ergonomie, préparée au Créapt, S. Volkoff et V. Pueyo (dir.). Noisy-le-Grand: Cnam, CEE.

\section{NOTA DO EDITOR}

Manuscrito recebido em : fevereiro/2013

Aceite após peritagem : maio/2013 
1 Esta tese trata das modalidades de gestão temporal da atividade em situações dinâmicas engajando processos múltiplos, notadamente plantas ornamentais no setor da horticultura (Zara-Meylan, 2012). O objetivo desse tipo de produção é levar as plantas à maturação com a qualidade esperada, repartindo os diferentes lotes segundo o planejamento de vendas da empresa. No entanto, este objetivo é difícil de ser alcançado nesses sistemas abertos à influências externas, pois as condições de cultura não são completamente controladas. Isto é agravado pelo contexto atual onde a lógica de racionalização entra em contradição com as necessidades de produção perecível, a ser controlada em condições variáveis.

2 Numa perspectiva ergonômica, a questão é saber como os trabalhadores, e particularmente os chefes de cultura encarregados das equipes de produção, gerenciam as exigências temporais múltiplas nesse contexto. Trata-se de compreender como eles integram os diferentes riscos ligados à eficácia da produção e aos trabalhadores. As análises se interessam também pelas discordâncias entre exigências oriundas de lógicas variadas, e estas oriundas do trabalho propriamente dito.

\section{Horticultura e viveiro de plantas, as dificuldades das pequenas empresas em busca de racionalização}

3 Esta pesquisa foi realizada em empresas de horticultura et de viveiro de plantas durante 3 projetos em parceria com outros institutos ${ }^{[1]}$, afim de responder a problemas de produção e de riscos profissionais. Nesse setor cada vez mais concorrencial, os dirigentes das empresas participantes à pesquisa insistem sobre a frágil situação econômica de suas estruturas, apesar do fato destas terem sido recentemente modernizadas e mecanizadas (irrigação, central climática, máquinas de semeio, ajudas ao carregamento de carga, etc.). Depois de algumas reflexões no setor, políticas comerciais mais ofensivas foram difundias e as lógicas de burocratização e de controle temporal rígido formam implementadas. Elas se concretizam em exigências de reatividade e de polivalência e em modos de prescrição e de avaliação do trabalho mais quantitativas, como por exemplo as medidas de cadência de produção (Pueyo \& ZaraMeylan, 2012). No entanto, as transformações não permitiram estabilizar a produção e as "problemas de qualidade" com perdas de clientes persistem. Além do mais, as restrições medicais complicam, segundo os dirigentes, as afetações as tarefas, conduzindo à questões sobre as competências dos trabalhadores, particularmente em alguns postos chave como o do chefe de cultura.

4 As situações observadas podem ser comparadas à outros setores, onde uma intensificação do trabalho se traduz em contraintes temporais cada vez menos dissociadas umas das outras (Askenazy, Cartron, de Coninck, \& Gollac, 2006 ; Volkoff, $2008,2012)$. Em horticultura, se constata um acúmulo dessas contraintes temporais e a associação delas é de difícil articulação pelos trabalhadores. Nota-se assim que os chefes de cultura encarregados da organização do trabalho são particularmente afetados por estas tensões. 


\section{A condução da cultura : uma articulação específica de exigências temporais}

5 Responsáveis pela produção no sitio e supervisores da atividade, a missão dos chefes de cultura é alcançar os objetivos fixados pelos dirigentes em termos de quantidade, de qualidade e de prazo, e ao mesmo tempo controlar os riscos para a produção e para a saúde dos trabalhadores. $O$ trabalho deles necessita saberes altamente especializados, para conduzir o desenvolvimento de produtos vivos e frágeis como as plantas. Eles se relacionam com os dirigentes, de quem eles recebem as instruções e à quem eles devem obedecer, e com os operários que tem o trabalho por eles organizado (um trabalho técnico no qual os chefes são também engajados). No mais, atores diversos (fornecedores, clientes, etc.) podem influenciar no trabalho dos chefes.

6 A tese defendida é que os chefes de cultura identificam e gerenciam, em um contexto complexo e dinâmico, diferentes exigências temporais imbricadas na atividade. Nós analisamos essas exigências temporais em termos de processo à seguir e em termos de "quadros temporais" que os chefes gerenciam no seus "meios temporais" de trabalho segundo o termo utilizado por W. Grossin. Fazendo uso dessas noções, nós mostraremos como a gestão integra as tensões e os riscos da atividades dos chefes, e como essa gestão pode ser complicada e até mesmo impedida segundo as diferentes configurações dos quadros temporais.

\section{Um movimento metodológico de desdobramento de várias dimensões temporais}

7 O desenvolvimento dessa tese se apoia num desdobramento, em três fases, das condições temporais do trabalho dos chefes de cultura :

- Uma fase exploratória é baseada na analise da organização da produção e das condições temporais do trabalho dos chefes em 9 sítios, em 6 empresas. As noções de processo, quadro e meio temporal são apresentadas.

- Em seguida os processos e os quadros temporais são examinados em diferentes configurações. A partir de entrevistas semi-dirigidas com 5 chefes de cultura, nós identificamos os agenciamentos e as configurações portadoras de ponto de referências em meio temporal. Algumas configurações são particularmente temidas tendo em vista os riscos e as dificuldades de gestão.

- As atividades imbricadas de dois chefes de cultura são em seguida examinadas à partir de observações sistemáticas de varias jornadas de trabalho. Nós analisamos a gestão dinâmica das tramas de quadros temporais em meio temporal.

8 Os principais resultados dessas três fases, assim que as principais noções mobilizadas na tese são resumidas em seguida.

\section{Os processos e os quadros temporais a gerenciar em meio temporal}

9 A horticultura se aparenta à uma condução de processo como descrito nas pesquisas sobre as situações dinâmicas (Amalberti, 2001 ; Cellier, De Keyser, \& Valot, 1996 ; Pueyo, 
2000). O trabalho é caracterizado pela complexidade, a variabilidade e a incerteza, presentes num sistema de produção à risco (Norros, 2004; Owen, 2009). O trabalho conhece um acúmulo e uma articulação especifica de condições temporais que nós examinamos em termos de processo, num vasto sentido, assim como de quadros temporais.

10 Os chefes de cultura devem gerenciar diferentes processos que não são simplesmente relativos às plantas, e que constituem cada um " um conjunto de fenômenos organizados no tempo" (Mendez et al., 2010, p. 7). Três tipos são identificados :

- Os processos de produção à seguir/acompanhar, tais como classicamente definidos em situação dinâmica, são aqui relacionados à dezenas ou até mesmo centenas de lotes de plantas, a acompanhar no mesmo momento afim de repartir a oferta comercial durante toda estação. Os processos são longos, durando vários meses no caso de plantas com flores, e vários anos no caso de arbústeos e árvores. Cada lote (plantas da mesma variedade no mesmo estado de produção) possui necessidades especificas e necessita cuidados à longo prazo (regar, podar, etc.), mas o estado das plantas é sempre instável. As culturas estando fora da terra ou em plena terra (grandes arvores), suas evoluções demandam diagnósticos frequentes e as vezes intervenções urgentes.

- As condições da biosfera (Shippers, 1997) são um conjunto de condições climáticas e bioquímicas de cultura (temperatura, higrometria, luminosidade, confinamento do ar, etc.) à serem controladas considerando a especificidade de cada parcela (orientação, modo de irrigação, etc.). Tanto no exterior ou sob abrigo, a biosfera é somente em parte controlada, pois ela está sempre sujeita à variações externas (clima, infestações de pestes, etc.). No mais, os problemas técnicos que a influenciam são numerosos (falhas do sistema de irrigação, janelas das serras bloqueadas...). Assim, previsões meteorológicas, diagnósticos generais e locais, antecipações, e intervenções reativas são necessárias.

- 0 processo de trabalho à ser realizado é outro fenômeno organizado, objeto de trabalho do chefe de cultura. Esse processo, cuja representação é elaborada através da experiência (Teiger, 1993 ; Weill-Fassina, 1990), necessita um trabalho de organização (de Terssac, 2002) feito de articulação e de ações técnicas e sociais com atores de lógicas diversas e dificilmente compatíveis (operários, dirigentes, comerciais, logísticas, etc.).

11 Outras condições temporais do trabalho dos chefes de cultura são abordadas sob o ângulo dos quadros temporais mais ou menos rígidos, tais como inicialmente teorizados em ecologia temporal (Grossin, 1996). Nos distinguimos 3 quadros em horticultura :

- Os quadros do planejamento das culturas fixam o calendário da cultura e da venda. Em cada empresa eles guiam fortemente a atividade, mesmo se eles são pouco formalizados, e sem cessa modificados por anulações de clientes, ou escolhas dos dirigentes para responder a um novo mercado, nem sempre antecipadas.

- Os quadros da organização do conjunto da produção são relacionados aos horários e aos calendários da semana de trabalho, e também à candência das maquinas, ao sistema de gestão e às normas que impõem articulações e medidas ; aos efetivos presentes, aos espaços que entram em jogo na repartição dos trabalhos, suas durações e seus deslocamentos.

- Os quadros temporais ditos fechados são relativos às condições locais do trabalho que podem ser diferentes de acordo com as tarefas e o posto. Eles provêm das instruções e dos procedimentos, das articulações internas à empresa (com o serviço comercial, por exemplo) ou externas (com os fornecedores ou clientes). 
12 De acordo com a situação, os processos e os quadros se traduzem em diferentes tipos de exigências (duração, ritmos e cadências impostas). Eles delimitam, constrangem e também estruturam e apoiam a atividade. Em uma perspectiva ergonômica, isto representa ao mesmo tempo contraintes (exigências) e recursos na atividade. Os chefes de cultura os colocam em relação para constituir o meio temporal.

13 Afim de detalhar a noção de meio temporal de trabalho no sentido em que ela é utilizada na tese, nós vamos examinar as configurações dos quadros temporais imbricados e suas formas de manifestação na atividade. Nós começamos por uma descrição dos agenciamentos e das configurações temporais, e em seguida por uma descrição das diferentes tramas de quadros temporais.

\section{Reunir os quadros temporais em agenciamentos e configurações}

14 Os agenciamentos sazonais associam os quadros temporais de condução das culturas (vendas em períodos precisos do calendário) e os principais processos de crescimento das plantas. Cinco tipos de agenciamentos, não exaustivos, aparecem nas nossas análises: os agenciamentos mono-sazonais (um quadro de início de cultura e um de venda), bi-sazonais (dois quadros de inicio de cultura se sobrepondo com dois quadros de venda), plurianual ( árvores controladas durante vários anos com vendas sobretudo invernais), mistas (condução mono ou bi-sazonais, com árvores), e em cascada (inicio de cultura e vendas se sucedem e se sobrepõem, por exemplo no caso de plantas com flores).

15 As configurações são compostas de relações dinâmicas (Elias, 1993 ; Grossin, 1996), periódicas ou eventuais, entre os quadros temporais e a organização do processo de trabalho. Algumas configurações esquematizam as situações habituais, frequentes ou repetitivas que os chefes têm para gerenciar; outras tratam de situações marcantes com relação as conjunções e encadeamento.

16 Algumas situações, contraditórias ou portadoras de riscos difíceis de serem evitados, são particularmente temidas pelos chefes de cultura (Pueyo, 2012 ; Valot, 1998). Um dos chefes descreve por exemplo uma configuração temida na primavera, associando exigências de processos de plantas, biosfera e trabalho, quando os quadros de venda tornam-se imperativos. Do fato do agenciamento bi-sazonal da condução nessa empresa, o chefe deve também iniciar novas culturas, novas plantas, enquanto se impõe um capinar suplementar para garantir as vendas. Esta configuração se conclui em riscos crescentes para a qualidade da produção cujos cuidados são retardados por causa das dores (dedos, joelhos, coluna), dos machucados, e da fadiga acumulada por toda a equipe.

17 As análises mostram diferentes modos de ação sobre os quadros temporais. No exemplo citado em seguida, o chefe de cultura reforça os quadros de tratamento das plantas (poda, capina, etc.) “ cada coisa no seu tempo", mesmo se o trabalho sempre ultrapassa os tempos prescritos. Afim de retardar um canteiro previsto nesse momento, ele tenta argumentar com os dirigentes "pra os bambus, vamos fazer também dos de 6 litros? Porque no ano passado...". Além do mais, ele alerta também sobre as consequências de uma multiplicação de pequenos lotes que complicam a articulação dos tratamentos e 
que podem agravar o atraso. Em caso de falha do material, ou atraso nas comandas, a única opção é se adaptar "eu corro, eu corro..." diz o chefe.

Assim, os riscos são não somente ligados à bifurcações não desejadas nos processos. Eles são ligados também ao fato do chefe não poder integrar as variações e os imprevistos na gestão das situações (Zara-Meylan, 2013).

\section{Articular as tramas dos quadros temporais}

19 Os chefes de cultura mantem a coerência de um conjunto de quadros temporais difíceis a serem conciliados, mas que eles conseguem organizar e articular. A analise da atividade mostra sucessões de episódios durante os quais eles realizam uma verdadeira gestão ativa e prospectiva do meio temporal, considerando a articulação das tramas complexas, mas inteligíveis (Le Moigne, 2009 ; Morin \& Le Moigne, 1999).

A gestão do meio temporal realizada pelos chefes de cultura é assim a ser apreendida além da ação do momento, num conjunto de outras ações efetuadas (Mead, 1967, 1st edt 1934), e inscritas num contexto de acompanhamento técnico e interação social (Joas, 2004, 1ère édt 1999 ; Pueyo, 2010). Esse conjunto de ações não é somente orientado por objetivos diretamente operativos, cujo resultado é sempre incerto no campo da horticultura. Ele concerne também a renovação e a abertura possível a outras ações.

\section{Os quadros e suas configurações na atividade, para transformar a relação da organização com respeito aos riscos}

Considerando o agir temporal como uma dimensão fundamental da atividade, essa pesquisa propõe uma estrutura para analisar as exigências do trabalho e favorizar a integração de critérios de riscos, pelos trabalhadores, durante a gestão das situações observadas.

22 As contribuições são discutidas do ponto de vista da pesquisa e da ação, esta última passando em particular por colaborações com os conselheiros em prevenção de riscos profissionais e por treinamento. Durante nossa pesquisa, a abordagem favorizou a visibilidade do trabalho real e do seu sentido para a organização e para os trabalhadores, com discussões coletivas com relação as fronteiras da zona do que é ou não aceitável. Ela permitiu transformar a relação da organização com respeito aos riscos.

23 As perspectivas consistem em reforçar o status dos agenciamentos, das configurações e das tramas dos quadros temporais, enquanto suportes úteis à ação sobre o trabalho. Pesquisas podem ser conduzidas nesse campo considerando o desenvolvimento, a experiência, as competências, a gestão temporal das dinâmicas da atividade em outras situações profissionais, tudo isso com uma visão e perspectiva sócio-históricas mais consequentes.

Amalberti, R. (2001). La maîtrise des situations dynamiques. Psychologie Française, 46(2), 105-117.

Askenazy, P., Cartron, D., de Coninck, F., \& Gollac, M. (Eds.). (2006). Organisation et intensité du travail. Toulouse Octarès. 
Cellier, J.-M., De Keyser, V., \& Valot, C. (1996). La gestion du temps dans les environnements dynamiques. Paris: PUF.

Elias, N. (1993). Engagement et distanciation. Paris: Fayard.

Grossin, W. (1996). Pour une science des temps. Introduction à l'écologie temporelle. Toulouse: Octarès.

Joas, H. (2004, 1ère édt 1999). La créativité de l'agir (P. Rusch, Trans.). Paris : Edition du Cerf.

Le Moigne, J.-L. (2009). L'Intelligence de l'Action appelle l'exercice de la Pensée Complexe. Pragmatique et Epistémique sont inséparables. Conférence introductive. Synergies Monde, 6, 23-48.

Mead, G. H. (1967, 1st edt 1934). Mind, Self and Society from the Standpoint of a Social Behaviorist (Vol. 1). Chicago: University of Chicago Press.

2 Mendez, A., Bidart, C., Brochier, D., Correia, M., Garnier, J., Gilson, A., et al. (2010). Chapitre introductif. Vers un système d'analyse des processus. In A. Mendez (Ed.), Processus. Concepts et méthode pour l'analyse temporelle en sciences sociales (pp. 11-26). Louvain-la-Neuve, Belgique: Bruyant-Academia.

Morin, E., \& Le Moigne, J.-L. (1999). L'intelligence de la complexité. Paris: L'Harmattan.

Norros, L. (2004). Acting under uncertainty. The core task analysis in ecological study of work: Espoo 2004. VTT Publications 546.

Owen, C. (2009). Accomplishing Reliability within Fallible Systems. In C. Owen, P. Béguin \& G. Wackers (Eds.), Risky Work Environments. Reappraising Human Work Within Fallible Systems (pp. 99-103). Farnham (G.B.): Ashgate.

Pueyo, V. (2000). La traque des dérives : expérience et maîtrise du temps, les atouts des “ anciens » dans une tâche d'autocontrôle. Travail et Emploi, 84, 63-73.

37 Pueyo, V. (2010). Quelle gestion de la sécurité dans une structure temporelle incertaine? La gestion des risques de pépiniéristes Actes du séminaire CREAPT Ages et Travail 2008. Rapport de recherche CEE $n^{\circ}$ 58. Expérience professionnelle et gestion de la sécurité au travail (Vol. www.cee-recherche.fr/, pp. 105-117). Paris : Centre d'Etudes de l'Emploi.

38 Pueyo, V. (2012). Quand la gestion des risques est en péril chez les fondeurs. In C. Gaudart, A.-F. Molinié \& V. Pueyo (Eds.), La vie professionnelle : âge, expérience et santé à l'épreuve des conditions de travail (pp. 257-284). Octarès.

9 Pueyo, V., \& Zara-Meylan, V. (2012). Impacts d'outils de gestion sur la conduite de cultures en pépinière. @ctivités, 9(1), 1-20 http://www.activites.org.

40 Shippers, T. K. (1997). Perceptions et domestications du cycle annuel, une approche ethno-écologique Les temps de l'environnement (Vol. Session 3, 4 \& 5, Conférences plénières, pp. 195-200). Toulouse.

41 Teiger, C. (1993). L'approche ergonomique : du travail humain à l'activité des hommes et des femmes au travail. Education Permanente, 116, 71-96.

de Terssac, G. (2002). Le travail d'organisation comme facteur de performance. In G. De Terssac (Ed.), Le Travail: une aventure collective. Recueil de textes (pp. 149-159). Toulouse: Octarès.

Valot, C. (1998). Métacognition et connaissances métacognitives. Intérêt pour l'ergonomie. Unpublished Thèse de doctorat de nouveau régime. Spécialité Ergonomie, Toulouse. 


\section{NOTAS}

1. A pesquisa se fez em parceria com ergonomistas do CREAPT e organismos de prevenção e de formação, e empresas da horticultura, durante 3 projetos :

- « Agriquadra », um projeto Equal sobre o envelhecimento e trabalho no setor agrícola, realizado em parceria com o Fonds national d'Assurance Formation des Salariés des Exploitations et entreprises Agricoles (FAFSEA), a Caisse Centrale de la Mutualité Sociale Agricole (CCMSA) et la Fédération Nationale des Producteurs de l'Horticulture et des Pépinières (FNPHP), de 2006 à 2008. - "L'évaluation des risques professionnels dans les pépinières ", segundo uma demanda do Bureau Réglementation et Travail du Ministère de l'Agriculture et de la Pêche en 2007.

- "Prévention des risques et préoccupations productives de petites entreprises ", em parceria com a MSA (mutualités sociales agricoles) do Languedoc e com a participação de empresas da horticultura, em 2009 e 2010.

\section{AUTORES}

\section{VALÉRIE ZARA-MEYLAN}

Centre d'Etudes de l'Emploi, Centre de Recherches sur l'Expérience, l'Age et les Populations au Travail, Immeuble Le Descartes 1, 29 promenade Michel Simon, 93166 Noisy-le-Grand, France valerie.meylan@cee-recherche.fr 